\title{
The development and validation of a nomogram for predicting brain metastases in lung squamous cell carcinoma patients: an analysis of the Surveillance, Epidemiology, and End Results (SEER) database
}

\author{
Jingya Zhang ${ }^{1 \#}$, Jiali Xü ${ }^{2 \#}$, Shidai Jin², Wen Gao ${ }^{2}$, Renhua Guo ${ }^{1}$, Liang Chen ${ }^{2}$ \\ ${ }^{1}$ Nanjing Medical University, First Affiliated Hospital of Nanjing Medical University, Nanjing, China; ${ }^{2}$ First Affiliated Hospital of Nanjing Medical \\ University, Nanjing, China \\ Contributions: (I) Conception and design: J Zhang, J Xu, S Jin, W Gao, R Guo, L Chen; (II) Administrative support: S Jin, W Gao, R Guo, L Chen; (III) \\ Provision of study materials or patients: J Zhang, J Xu; (IV) Collection and assembly of data: J Xu; (V) Data analysis and interpretation: J Zhang; (VI) \\ Manuscript writing: All authors; (VII) Final approval of manuscript: All authors. \\ \#These authors contributed equally to this work. \\ Correspondence to: Renhua Guo. Nanjing Medical University, First Affiliated Hospital of Nanjing Medical University, Nanjing 210000, China. Email: \\ rhguonjmu@sina.com; Liang Chen. First Affiliated Hospital of Nanjing Medical University, Nanjing 210000, China. Email: cl_big@yahoo.com.cn.
}

Background: The incidence of brain metastasis (BM) in patients suffering from lung squamous cell carcinoma (LUSC) is lower than that in patients suffering from non-squamous cell carcinoma (NSCC) and there are few studies on BM of LUSC. The purpose of this investigation was to ascertain the risk factors of LUSC, as well as to establish a nomogram prognostic model to predict the incidence of BM in patients with LUSC.

Methods: Patients diagnosed with LUSC between 2010 and 2015 were identified from the Surveillance, Epidemiology, and End Results (SEER) database and the patient data were collated. All patients diagnosed from 2010-2012 were allocated into the training cohort, and the remaining patients diagnosed from 20132015 formed the test cohort. Using factors that were screened out through logistic regression analyses, the nomogram in the training cohort was established. It was then evaluated for discrimination and calibration using the test cohort. The performance of the nomogram was assessed by quantifying the area under the receiver operating characteristic (ROC) curve and evaluating the calibration curve.

Results: A total of 26,154 LUSC patients were included in the study. The training cohort consisted of 16,543 patients and there were 8611 patients in the test cohort. Age, marital status, insurance status, histological grade, tumor location, laterality, stage of the cancer, number of metastatic organs, chemotherapy, surgery, and radiotherapy were highly correlated with the incidence of BM. The area under the ROC curve (AUC) of the nomogram for the training cohort and the test cohort were 0.810 [95\% confidence interval (CI): 0.796 to 0.823 ] and 0.805 (95\% CI: 0.784 to 0.825 ), respectively. The slope of the calibration curve was close to 1 .

Conclusions: The nomogram was able to accurately predict the incidence of BM. This may be beneficial for the early identification of high-risk LUSC patients and the establishment of individualized treatments.

Keywords: Lung squamous cell carcinoma (LUSC); predicting model; brain metastasis (BM); database

Submitted Oct 30, 2020. Accepted for publication Jan 19, 2021.

doi: $10.21037 /$ jtd-20-3494

View this article at: http://dx.doi.org/10.21037/jtd-20-3494 


\section{Introduction}

Lung cancer patients who present with brain metastasis (BM) usually have poor prognosis (1-3). These patients place a significant burden on their family caregivers, the nursing staff and the society (4-7). Only early diagnosis and timely therapy can improve their rate of survival (8-11). Currently, the NCCN/ACCP (National Comprehensive Cancer Network/American College of Chest Physicians) does not recommend the screening of asymptomatic patients with stage I non-small cell lung cancer (NSCLC) because stage I NSCLC are less likely to have BM $(12,13)$. However, BM may occur in patients with early-stage NSCLC even in the absence of any neurological symptoms. Whether conventional brain imaging, such as magnetic resonance imaging (MRI) of the brain, should be used in all cases remains controversial (14). If BM can be predicted prior to brain MRI imaging with the use of a nomogram, asymptomatic early-stage NSCLC patients could avoid missed or delayed diagnoses. The incidence of BM is lower in patients with lung squamous cell carcinoma (LUSC) compared to those with non-squamous cell carcinoma (NSCC) and there are few studies on BM of LUSC $(15,16)$. Efficient tools are urgently needed to facilitate the early diagnosis of BM in patients with LUSC (17).

The "seed and soil hypothesis" has been proposed to explain the pathogenesis of BM (18). Nomograms have shown favorable efficiency in predicting risks and outcomes in various cancers, such as breast cancer and intestinal cancer (19). Therefore, in this study, a new nomogram was established to predict the risk of BM in LUSC patients.

We present the following article in accordance with the TRIPOD reporting checklist (available at http://dx.doi. org/10.21037/jtd-20-3494).

\section{Methods}

\section{Ethical statement}

The study was conducted in accordance with the Declaration of Helsinki (as revised in 2013). The data were collected from the Surveillance, Epidemiology, and End Results (SEER) data library. Informed consent was not required as cancer is classified as an informed illness in the United States of America.

\section{Patient selection}

The SEER *Stat Software (version 8.3.4) was applied to create the tabulation of all cases. Patients who were pathologically confirmed with LUSC from the SEER database during 2010-2015 were included. The exclusion criteria included the following: non-first primary LUSC; unknown brain metastases; incomplete data regarding gender, race, marital status, insurance status, grade of tumor, tumor location, laterality, and $\mathrm{T}$ or $\mathrm{N}$ cancer staging (as defined by the 7th edition of the American Joint Committee on Cancer (AJCC) staging system); bone, liver or lung metastasis; and unknown history of chemotherapy, surgery or radiotherapy. The patients diagnosed with LUSC during 2010-2012 and 2013-2015 exhibited comparable clinical pathological characteristics, therefore the training cohort included patients who were diagnosed during the period from 2010 to 2012, while the test cohort included patients who were diagnosed between 2013 and 2015 .

\section{Statistical analysis}

The Pearson chi-square test or Fisher's exact test was used to contrast the variables between the training cohort and the test cohort. Regression analysis was utilized to screen out risk elements of $\mathrm{BM}$ that were then further submitted to multivariate analysis. The odds ratio (OR) was expressed as the $95 \%$ confidence interval (CI). The nomogram was established using the training cohort data and then discrimination and calibration were evaluated using the test cohort. Variables (such as tumor location) with $\mathrm{P}<0.05$ were incorporated into the nomogram. The likelihood-ratio test was applied to select the proper model.

The discrimination performance of the nomogram was quantified by the area under the receiver operating characteristic (ROC) curve (AUC). By drawing the relationship between the observed and predicted incidences, the nomogram was calibrated with the Hosmer goodnessof-fit measurement. The bootstrap method (1,000 replicates) was employed for the internal verification of performance. Overall checkouts were two sided. Results were considered statistically different when $\mathrm{P}<0.05$. Statistical analysis was performed using the SPSS 3.5.1 software.

\section{Results}

\section{Patient characteristics}

The study cohort included 26,154 patients diagnosed during 2010-2015, with 17,543 patients in the training cohort and 
8611 patients in the test cohort. Most patients were elderly whose average age was 67 . The clinical characteristics in both cohorts are shown in Table 1. The median survival of LUSC patients with BM was evidently shorter than LUSC patients without BM. Similarly, patients with BM had significantly lower lung cancer-specific survival (LSCC) and overall survival (OS) compared to patients without BM (Figure 1).

\section{Factors associated with BM}

Univariate Cox regression analysis was conducted in the training cohort. As shown in Table 2, gender and race showed no significant relationship with BM. However, the factors most closely associated with BM were age at the time of diagnosis, marital status, insurance, microanatomy grade, tumor location, laterality, number of organs with metastases, chemotherapy, surgery, and radiation. These factors were then submitted to multivariate Cox logistic regression analysis (Table 3). The outcomes demonstrated that age at the time of diagnosis, tumor grade, tumor stage, number of organs with metastases, chemotherapy, surgery, and radiation were independent factors for predicting BM. Therefore, these elements were used to establish the nomogram prognostic model. Tumor location $(\mathrm{P}<0.07)$ was also included (Table 3).

\section{Construction of the nomogram}

The nomogram was established by incorporating age at

Table 1 Patient demographics and clinical characteristics

\begin{tabular}{|c|c|c|c|c|c|c|}
\hline \multirow{2}{*}{ Characteristics } & \multicolumn{2}{|c|}{ All patients } & \multicolumn{2}{|c|}{ Training group } & \multicolumn{2}{|c|}{ Validation group } \\
\hline & $n=26,154$ & $\%$ & $n=17,543$ & $\%$ & $\mathrm{n}=8,611$ & $\%$ \\
\hline All cause & 15,762 & & 12,525 & & 3,237 & \\
\hline LCSS & 13,193 & & 10,431 & & 2,762 & \\
\hline \multicolumn{7}{|l|}{ Age at diagnosis (year) } \\
\hline$<50$ & 603 & 2.3 & 435 & 2.5 & 168 & 2 \\
\hline $50-70$ & 11,940 & 45.7 & 8,090 & 46.1 & 3,850 & 44.7 \\
\hline$>70$ & 13,611 & 52 & 9,018 & 51.4 & 4,593 & 53.3 \\
\hline \multicolumn{7}{|l|}{ Gender } \\
\hline Male & 16,262 & 62.2 & 10,953 & 62.4 & 5,309 & 61.7 \\
\hline Female & 9,892 & 37.8 & 6,590 & 37.6 & 3,302 & 38.3 \\
\hline \multicolumn{7}{|l|}{ Race } \\
\hline White & 21,915 & 83.3 & 14,745 & 84.1 & 7,170 & 83.3 \\
\hline Black & 2,939 & 11.2 & 1,950 & 11.1 & 989 & 11.5 \\
\hline $\begin{array}{l}\text { Other (American Indian/Alaskan } \\
\text { Native, Asian/Pacific Islander) }\end{array}$ & 1,300 & 5 & 848 & 4.8 & 452 & 5.2 \\
\hline \multicolumn{7}{|l|}{ Marital status } \\
\hline Single & 3,599 & 13.8 & 2,340 & 13.3 & 1,259 & 14.6 \\
\hline Married & 13,083 & 50 & 8,833 & 50.4 & 4,250 & 49.4 \\
\hline Other & 9,472 & 36.2 & 6,370 & 36.3 & 3,102 & 36 \\
\hline \multicolumn{7}{|l|}{ Insurance } \\
\hline No & 895 & 3.4 & 671 & 3.8 & 224 & 2.6 \\
\hline Yes & 25,259 & 96.6 & 16,872 & 96.2 & 8,387 & 97.4 \\
\hline
\end{tabular}

Table 1 (continued) 
Table 1 (continued)

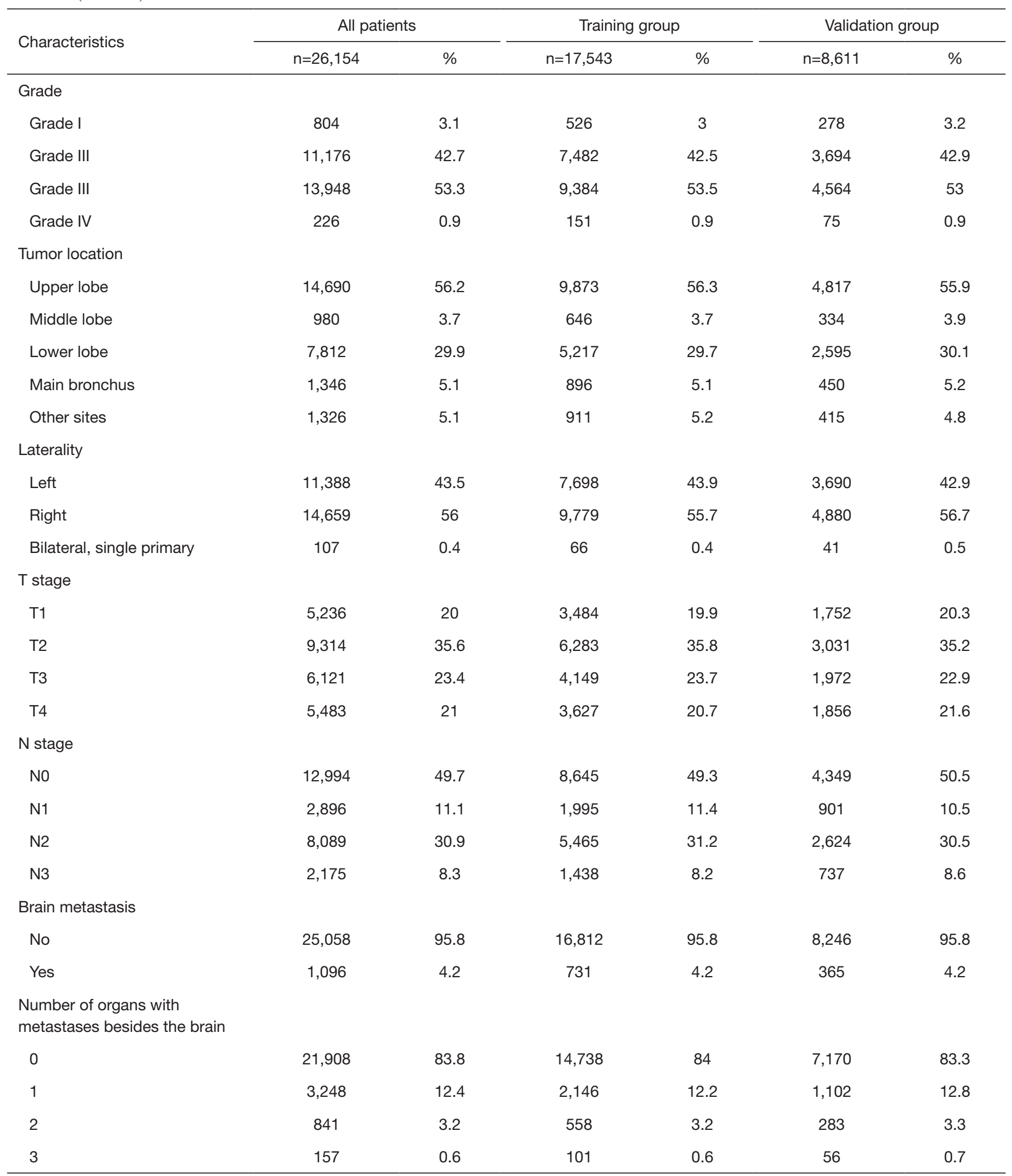

Table 1 (continued) 
Table 1 (continued)

\begin{tabular}{|c|c|c|c|c|c|c|}
\hline Characteristics & \multicolumn{2}{|c|}{ All patients } & \multicolumn{2}{|c|}{ Training group } & \multicolumn{2}{|c|}{ Validation group } \\
\hline \multicolumn{7}{|l|}{ Bone metastasis } \\
\hline No & 24,140 & 92.3 & 16,217 & 92.4 & 7,924 & 92 \\
\hline Yes & 2,014 & 7.7 & 1,326 & 7.6 & 688 & 8 \\
\hline No & 25,102 & 96 & 16,841 & 96 & 8,261 & 95.9 \\
\hline Yes & 1,052 & 4 & 702 & 4 & 350 & 4.1 \\
\hline \multicolumn{7}{|l|}{ Lung metastasis } \\
\hline No & 23,819 & 91.1 & 16,006 & 91.2 & 7,813 & 90.7 \\
\hline No & 15,158 & 58 & 10,213 & 58.2 & 4,945 & 57.4 \\
\hline Yes & 10,996 & 42 & 7,330 & 41.8 & 3,666 & 42.6 \\
\hline \multicolumn{7}{|l|}{ Surgery } \\
\hline No & 16,344 & 62.5 & 10,751 & 61.3 & 5,593 & 65 \\
\hline Yes & 9,810 & 37.5 & 6,792 & 38.7 & 3,018 & 35 \\
\hline \multicolumn{7}{|l|}{ Radiotherapy } \\
\hline No & 14,736 & 56.3 & 9,974 & 56.9 & 4,762 & 55.3 \\
\hline Yes & 11,418 & 43.7 & 7,569 & 43.1 & 3,849 & 44.7 \\
\hline
\end{tabular}

A

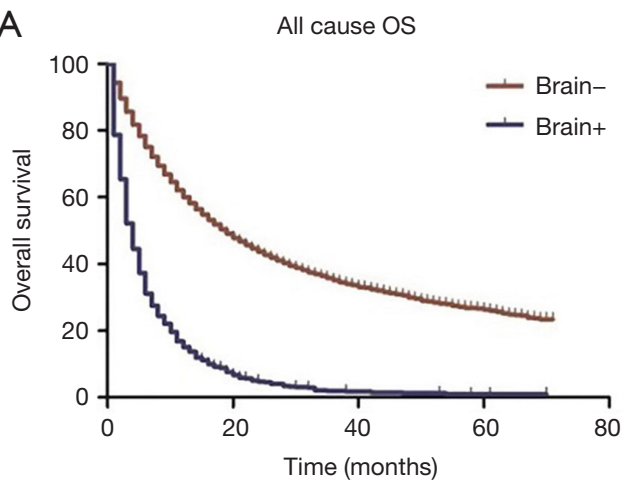

B

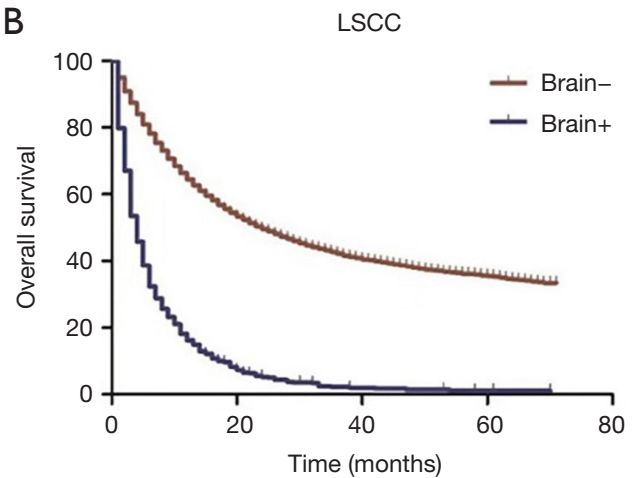

Figure 1 Kaplan-Meier survival curves. (A) Kaplan-Meier survival curves for LUSC patients showing overall survival. (B) Kaplan-Meier survival curves for LUSC patients showing lung cancer specific survival. Log-rank P values were both $<0.0001$. LUSC, lung squamous cell carcinoma.

diagnosis, grade, the location of tumor, $\mathrm{T}$ and $\mathrm{N}$ stage, number of metastases, chemotherapy, surgery, and radiation (Figure 2). The AUC of the nomogram was 0.810 (95\% CI: 0.796 to 0.823 ) and 0.805 (95\% CI: 0.784 to 0.825$)$ in the training cohort and the test cohort, respectively, suggesting a good predictive ability (Figure $3 A, B$ ). The calibration curve showed a high consistency between the observed and predicted survival (Figure 3C,D). 
Table 2 Univariate Cox logistic regression analysis for both cohorts

\begin{tabular}{|c|c|c|c|c|c|c|}
\hline Characteristics & \multicolumn{3}{|c|}{ Training group, no. (\%) } & \multicolumn{3}{|c|}{ Validation group, no. (\%) } \\
\hline Age at diagnosis (year) & & & $<0.0001$ & & & $<0.0001$ \\
\hline$<50$ & $394(2.3)$ & $41(5.6)$ & & $152(1.8)$ & $16(4.4)$ & \\
\hline $50-70$ & $7,695(45.8)$ & $395(54.0)$ & & $3,645(44.2)$ & $205(56.2)$ & \\
\hline Gender & & & 0.584 & & & 0.660 \\
\hline Male & $10,489(62.4)$ & $464(63.5)$ & & $5,088(61.7)$ & $221(60.5)$ & \\
\hline Female & 6,323 (37.6) & 267 (36.5) & & $3,158(38.3)$ & $144(39.5)$ & \\
\hline Race & & & 0.198 & & & 0.013 \\
\hline $\begin{array}{l}\text { Other (American Indian/Alaskan } \\
\text { Native, Asian/Pacific Islander) }\end{array}$ & $808(4.8)$ & $40(5.5)$ & & $431(5.2)$ & $21(5.8)$ & \\
\hline Marital status & & & 0.004 & & & 0.309 \\
\hline Single & 2,216 (13.2) & $124(17.0)$ & & $1,197(14.5)$ & $62(17.0)$ & \\
\hline Married & $8,461(50.3)$ & $372(50.9)$ & & $4,068(49.3)$ & $182(49.9)$ & \\
\hline Other & $6,135(36.5)$ & $235(32.1)$ & & $2,981(36.2)$ & $121(33.2)$ & \\
\hline Insurance & & & 0.008 & & & 0.004 \\
\hline No & $629(3.7)$ & $42(5.7)$ & & $205(2.5)$ & $19(5.2)$ & \\
\hline Undifferentiated; Grade IV & $140(0.8)$ & $11(1.5)$ & & $71(0.9)$ & $4(1.1)$ & \\
\hline Tumor location & & & 0.008 & & & 0.013 \\
\hline Upper lobe & $9,486(56.4)$ & 387 (52.9) & & $4,620(56.0)$ & $197(54.0)$ & \\
\hline Middle lobe & $612(3.6)$ & $34(4.7)$ & & 319 (3.9) & $15(4.1)$ & \\
\hline Lower lobe & $5,009(29.8)$ & $208(28.5)$ & & $2,497(30.3)$ & $98(26.8)$ & \\
\hline Main bronchus & $846(5.0)$ & $50(6.8)$ & & $425(5.2)$ & $25(6.8)$ & \\
\hline Other sites & $859(5.1)$ & $52(7.1)$ & & $385(4.7)$ & $30(8.2)$ & \\
\hline Laterality & & & 0.024 & & & 0.003 \\
\hline Left & $7,389(44.0)$ & $309(42.3)$ & & $3,542(43.0)$ & $148(40.5)$ & \\
\hline Right & $9,364(55.7)$ & $415(56.8)$ & & $4,669(56.6)$ & $211(57.8)$ & \\
\hline Bilateral, single primary & $59(0.4)$ & $7(1.0)$ & & $35(0.4)$ & $6(1.6)$ & \\
\hline
\end{tabular}

Table 2 (continued) 
Table 2 (continued)

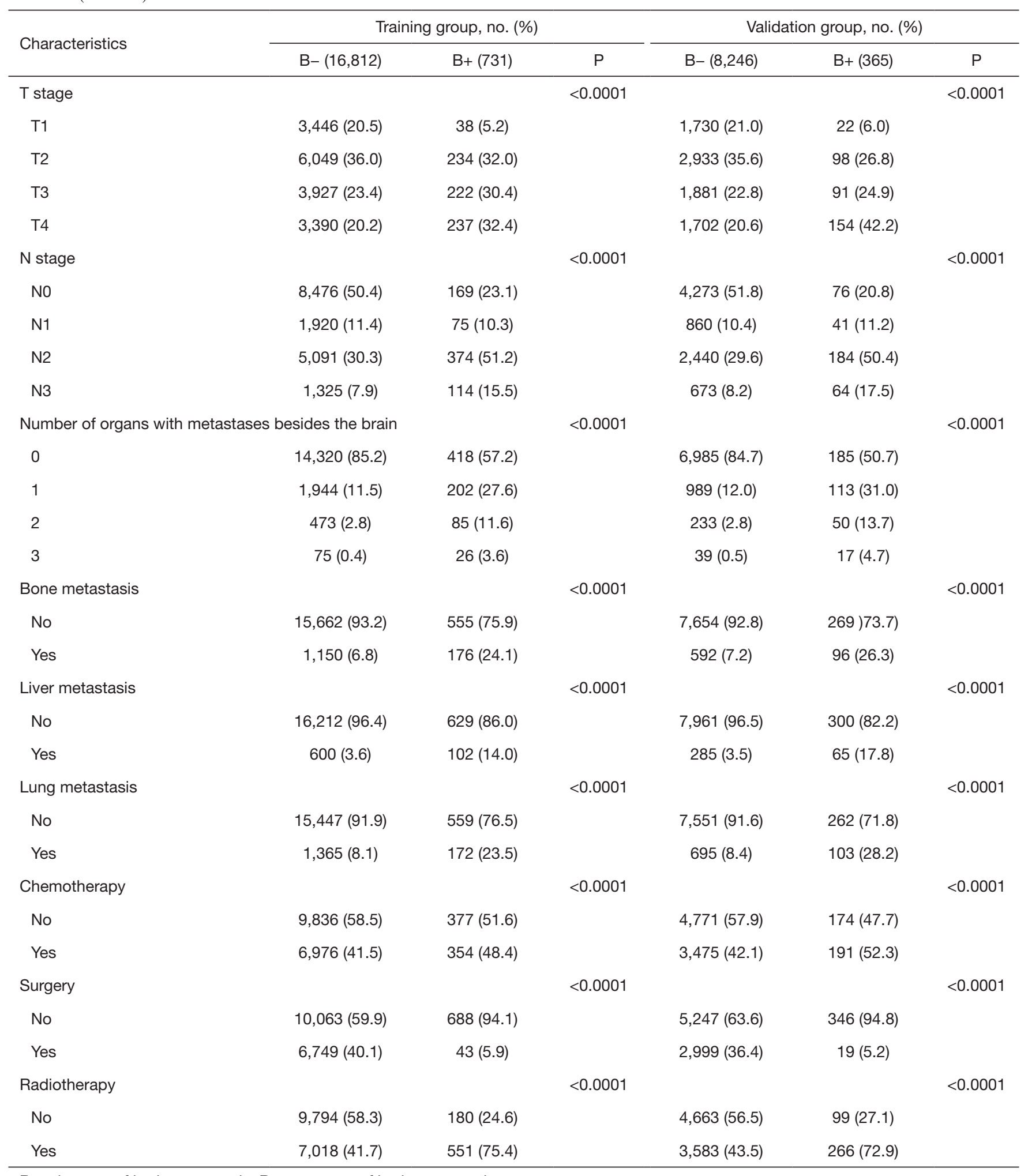

$\mathrm{B}-$, absence of brain metastasis; $\mathrm{B}+$, presence of brain metastasis. 
Table 3 Multivariate Cox logistic regression analysis to discriminate risk elements of LUSC in the training cohort

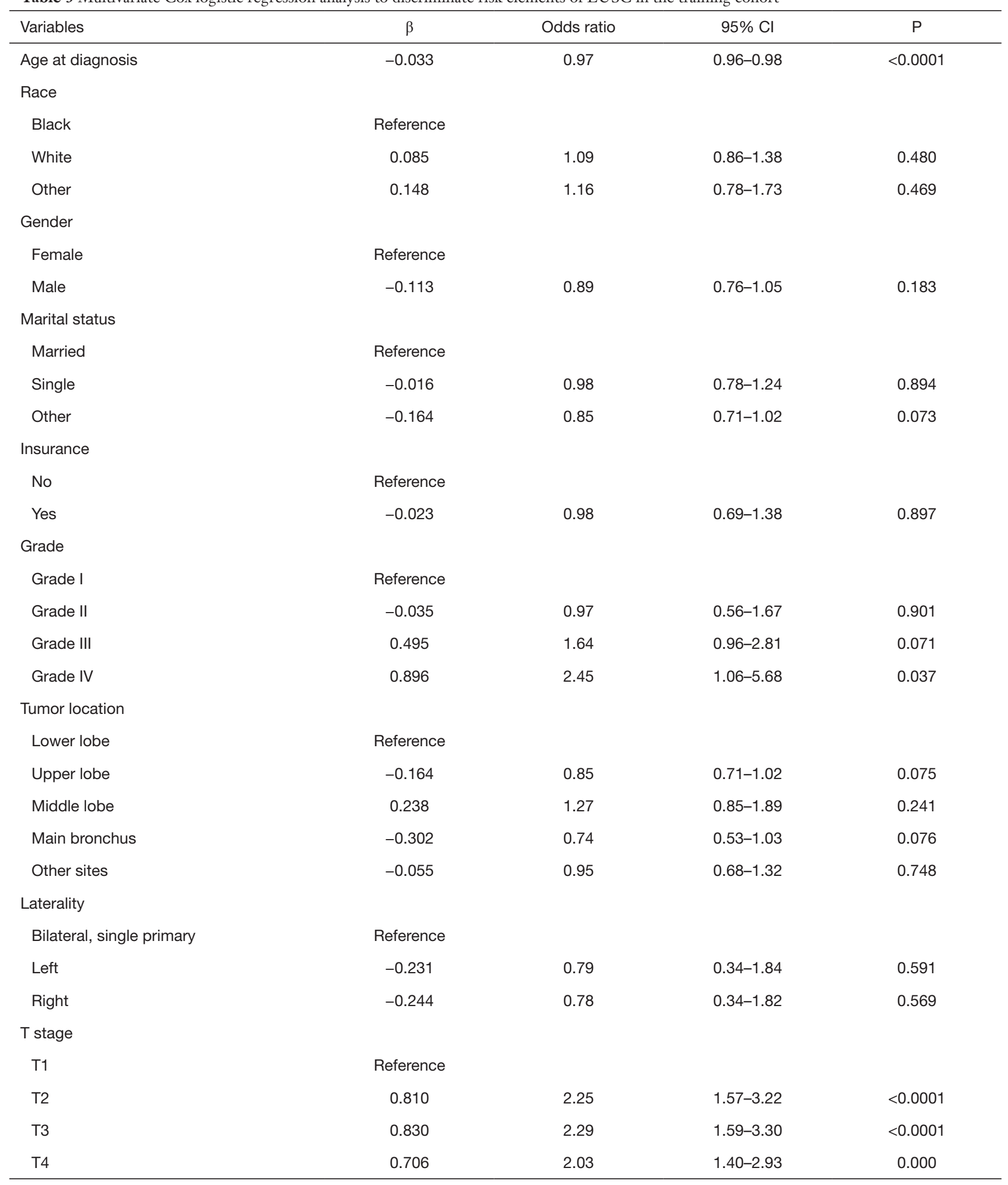

Table 3 (continued) 
Table 3 (continued)

\begin{tabular}{|c|c|c|c|c|}
\hline Variables & $\beta$ & Odds ratio & $95 \% \mathrm{Cl}$ & $\mathrm{P}$ \\
\hline \multicolumn{5}{|l|}{$\mathrm{N}$ stage } \\
\hline NO & Reference & & & \\
\hline $\mathrm{N} 1$ & 0.474 & 1.61 & $1.20-2.14$ & 0.001 \\
\hline N2 & 0.479 & 1.61 & $1.32-1.98$ & $<0.0001$ \\
\hline Number of metastases besides the brain & 0.663 & 1.94 & $1.75-2.15$ & $<0.0001$ \\
\hline \multicolumn{5}{|l|}{ Chemotherapy } \\
\hline No & Reference & & & \\
\hline Yes & -0.614 & 0.54 & $0.46-064$ & $<0.0001$ \\
\hline Yes & -1.492 & 0.22 & $0.16-0.31$ & $<0.0001$ \\
\hline \multicolumn{5}{|l|}{ Radiation } \\
\hline \multicolumn{5}{|l|}{ No } \\
\hline Yes & 1.171 & 3.23 & $2.67-3.90$ & $<0.0001$ \\
\hline
\end{tabular}

LUSC, lung squamous cell carcinoma; $\beta$ is the regression coefficient.

Points
Age
Grade
Location
T.stage
N.stage
Number.of.metastates
Chemotherapy
Surgery
Radiation
Total Points
Risk

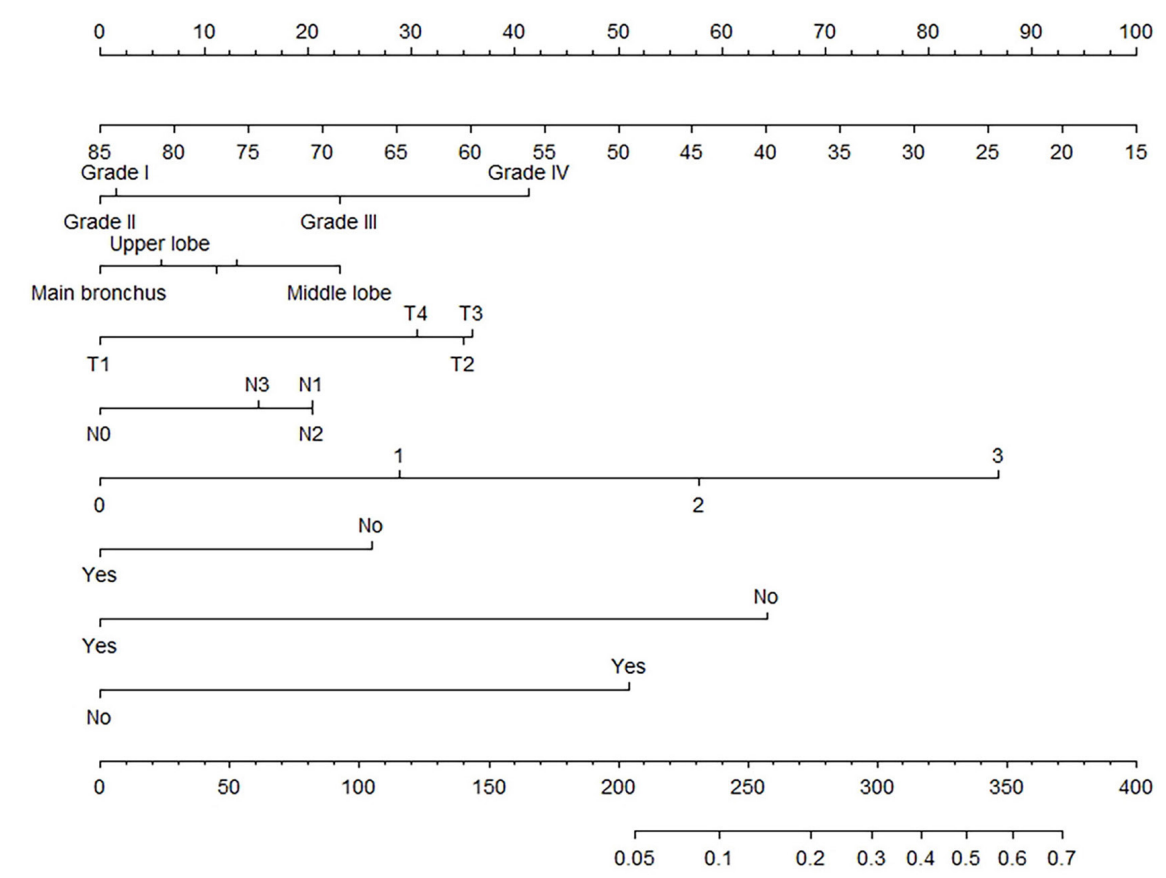

Figure 2 Nomogram predicting BM in patients with SCC. The first row illustrates the point allocation of every variable. Lines $2-10$ represent the alternating quantity contained in the nomogram. For each patient, each variable of LSCC was given a score. The scores were totaled and illustrated in line 11 . The bottom row presents the probability of BM. BM, brain metastasis; SCC, squamous cell carcinoma; LSCC, lung cancer specific survival. 

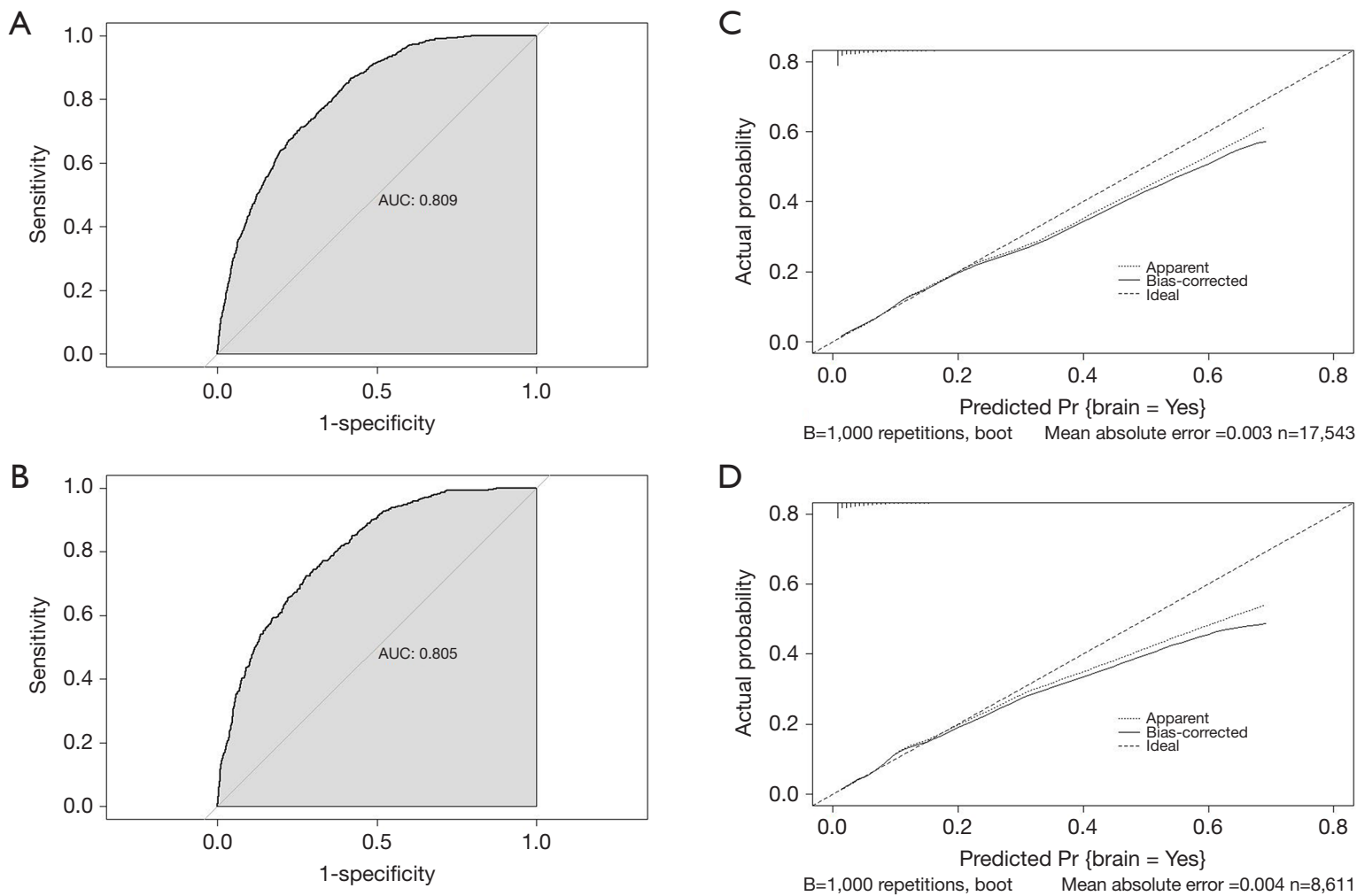

Figure 3 Discrimination and calibration of the nomogram. (A) and (B) ROC for discrimination. The AUC of the nomogram is 0.810 (95\% CI: 0.796 to 0.823 ) and 0.805 (95\% CI: 0.784 to 0.825$)$ in the training cohort and the test cohort, respectively. (C) and (D) Calibration of the nomogram. The $\mathrm{x}$-axis represents the BM probabilities predicted by the nomogram, while the $y$-axis represents the observed probabilities. The plummet lines express the frequency distribution of the forecast probability. The dotted line represents the match between two probabilities. The calibration curve shows good predictive ability of the nomogram. ROC, receiver operating characteristic; AUC, area under the curve; CI, confidence interval; BM, brain metastasis.

\section{Discussion}

Our research is the first to report a nomogram for predicting $\mathrm{BM}$ in patients with LUSC. This nomogram provides an efficient and convenient tool for early diagnosis of BM thereby allowing for the implementation of timely treatment strategies. Previous studies have demonstrated similar BM pathogenesis in patients with LUSC and lung adenocarcinoma (LUAD) (20-23). Muniz et al. found that the incidence of $\mathrm{BM}$ increased with age in patients with LUSC and LUAD (24), which is consistent with our results. Univariate and multivariate Cox logistic regression analyses demonstrated that age at diagnosis, tumor grade, location of tumor, tumor stage, number of organs with metastases, chemotherapy, surgery, and radiation were independent factors that could predict the incidence of BM. These factors were used to establish a prediction nomogram. The predictive accuracy was validated, with AUC of 0.810 (95\% CI: 0.796 to 0.823 ) and 0.805 (95\% CI: 0.784 to 0.825 ) in the training cohort and the test cohort, respectively. These results support the potential use of this nomogram in clinical practice, especially in the establishment of individualized treatments.

However, due to the retrospective nature of this study, selection bias may exist. As new treatments continue to be developed for the improved survival of LUSC patients, this current nomogram should be renewed with additional clinical data, such as types of surgical treatment, radiotherapy dosage, and chemotherapy regimens. Furthermore, due to insufficient data, our nomogram could only be validated internally $(19,25)$ and hence, validation with larger data cohorts and longer follow-up times will be required. 


\section{Conclusions}

The nomogram could accurately predict the incidence of $\mathrm{BM}$, which is helpful in the early identification of highrisk LUSC patients and the establishment of individualized treatments.

\section{Acknowledgments}

Funding: None.

\section{Footnote}

Reporting Checklist: The authors have completed the TRIPOD reporting checklist. Available at http://dx.doi. org/10.21037/jtd-20-3494

Conflicts of Interest: All authors have completed the ICMJE uniform disclosure form (available at http://dx.doi. org/10.21037/jtd-20-3494). The authors have no conflicts of interest to declare.

Ethical Statement: The authors are accountable for all aspects of the work in ensuring that questions related to the accuracy or integrity of any part of the work are appropriately investigated and resolved. The study was conducted in accordance with the Declaration of Helsinki (as revised in 2013). The institutional review board approval was waived for this study as the SEER database is a public anonymized database. The author Zhang obtained access to the SEER database (accession number: 13013-Nov2019). The data issued in the SEER database do not require consent from patients as cancer is an informed illness in every state of the United States of America.

Open Access Statement: This is an Open Access article distributed in accordance with the Creative Commons Attribution-NonCommercial-NoDerivs 4.0 International License (CC BY-NC-ND 4.0), which permits the noncommercial replication and distribution of the article with the strict proviso that no changes or edits are made and the original work is properly cited (including links to both the formal publication through the relevant DOI and the license). See: https://creativecommons.org/licenses/by-ncnd $/ 4.0 \%$.

\section{References}

1. Cagney DN, Martin AM, Catalano PJ, et al. Incidence and prognosis of patients with brain metastases at diagnosis of systemic malignancy: a population-based study. Neuro Oncol 2017;19:1511-21.

2. $\mathrm{Xu} X$, Huang $\mathrm{L}$, Chen J, et al. Application of radiomics signature captured from pretreatment thoracic CT to predict brain metastases in stage III/IV ALK-positive nonsmall cell lung cancer patients. J Thorac Dis 2019;11:4516-28.

3. Kamer I, Steuerman Y, Daniel-Meshulam I, et al. Predicting brain metastasis in early stage non-small cell lung cancer patients by gene expression profiling. Transl Lung Cancer Res 2020;9:682-92.

4. Hengel K, Sidhu G, Choi J, et al. Attributes of brain metastases from breast and lung cancer. Int J Clin Oncol 2013;18:396-401.

5. Nathoo N, Chahlavi A, Barnett GH, et al. Pathobiology of brain metastases. J Clin Pathol 2005;58:237-42.

6. Peng H, Tan H, Zhao W, et al. Computational systems biology in cancer brain metastasis. Front Biosci (Schol Ed) 2016;8:169-86.

7. Singh M, Venugopal C, Tokar T, et al. Therapeutic Targeting of the Premetastatic Stage in Human Lung-toBrain Metastasis. Cancer Res 2018;78:5124-34.

8. Goncalves PH, Peterson SL, Vigneau FD, et al. Risk of brain metastases in patients with nonmetastatic lung cancer: Analysis of the Metropolitan Detroit Surveillance, Epidemiology, and End Results (SEER) data. Cancer 2016;122:1921-7.

9. Gu X, Zhao Y, Xu F. Whole Brain Irradiation and Hypo-fractionation Radiotherapy for the Metastases in Non-small Cell Lung Cancer. Zhongguo Fei Ai Za Zhi 2016;19:224-9.

10. Guillamo JS, Emery E, Busson A, et al. Current management of brain metastases. Rev Neurol (Paris) 2008; 164:560-8.

11. Inoue HK, Seto K, Nozaki A, et al. Three-fraction CyberKnife radiotherapy for brain metastases in critical areas: referring to the risk evaluating radiation necrosis and the surrounding brain volumes circumscribed with a single dose equivalence of 14 Gy (V14). J Radiat Res 2013;54:727-35.

12. Ettinger DS, Wood DE, Aisner DL, et al. Non-Small Cell Lung Cancer, Version 5.2017, NCCN Clinical Practice Guidelines in Oncology. J Natl Compr Canc Netw 2017;15:504-35.

13. Silvestri GA, Gonzalez AV, Jantz MA, et al. Methods for staging non-small cell lung cancer: Diagnosis and management of lung cancer, 3rd ed: American College 
of Chest Physicians evidence-based clinical practice guidelines. Chest 2013;143:e211S-50S.

14. Ando T, Kage H, Saito M, et al. Early stage non-small cell lung cancer patients need brain imaging regardless of symptoms. Int J Clin Oncol 2018;23:641-6.

15. Mujoomdar A, Austin JH, Malhotra R, et al. Clinical predictors of metastatic disease to the brain from nonsmall cell lung carcinoma: primary tumor size, cell type, and lymph node metastases. Radiology 2007;242:882-8.

16. Shi AA, Digumarthy SR, Temel JS, et al. Does initial staging or tumor histology better identify asymptomatic brain metastases in patients with non-small cell lung cancer? J Thorac Oncol 2006;1:205-10.

17. Xu Y, Li H, Huang Z, et al. Predictive values of genomic variation, tumor mutational burden, and PD-L1 expression in advanced lung squamous cell carcinoma treated with immunotherapy. Transl Lung Cancer Res 2020;9:2367-79.

18. Ebben JD, You M. Brain metastasis in lung cancer: Building a molecular and systems-level understanding to improve outcomes. Int J Biochem Cell Biol 2016;78:288-96.

19. Wang T, Lu R, Lai S, et al. Development and Validation of a Nomogram Prognostic Model for Patients With Advanced Non-Small-Cell Lung Cancer. Cancer Inform 2019;18:1176935119837547.

20. Behrens C, Solis LM, Lin H, et al. EZH2 protein expression associates with the early pathogenesis, tumor

Cite this article as: Zhang $\mathrm{J}, \mathrm{Xu} \mathrm{J}$, Jin S, Gao W, Guo R, Chen $L$. The development and validation of a nomogram for predicting brain metastases in lung squamous cell carcinoma patients: an analysis of the Surveillance, Epidemiology, and End Results (SEER) database. J Thorac Dis 2021;13(1):270-281. doi: 10.21037/jtd-20-3494 progression, and prognosis of non-small cell lung carcinoma. Clin Cancer Res 2013;19:6556-65.

21. Jiang $M$, Zhu X, Han X, et al. Histologic transformation of non-small-cell lung cancer in brain metastases. Int J Clin Oncol 2019;24:375-84.

22. Fábián K, Németh Z, Furák J, et al. Protein expression differences between lung adenocarcinoma and squamous cell carcinoma with brain metastasis. Anticancer Res 2014;34:5593-7.

23. Kuremsky JG, Urbanic JJ, Petty WJ, et al. Tumor histology predicts patterns of failure and survival in patients with brain metastases from lung cancer treated with gamma knife radiosurgery. Neurosurgery 2013;73:641-7; discussion 647.

24. Muniz TP, de Jesus VHF, Sousa VAR, et al. A modified recursive partitioning analysis for predicting overall survival in patients with non-small cell lung cancer and central nervous system metastases. J Thorac Dis 2019;11:3909-19.

25. Zheng XQ, Huang JF, Lin JL, et al. Incidence, prognostic factors, and a nomogram of lung cancer with bone metastasis at initial diagnosis: a population-based study. Transl Lung Cancer Res 2019;8:367-79.

(English Language Editor: J. Teoh) 